\title{
POLÍTICA LINGUÍSTICA PARA O ENSINO DE LÍNGUAS: A IMPLANTAÇÃO DO ENSINO DE ESPANHOL NAS ESCOLAS DE ARAGUATINS
}

\author{
POLÍTICA LINGÜÍSTICA PARA LA ENSEÑANZA DE LENGUAS: \\ LA IMPLANTACIÓN DE LA ENSEÑANZA DE ESPAÑOL EN LAS ESCUELAS DE \\ ARAGUATINS
}

\author{
Nívea Oliveira Santos Bersch ${ }^{1}$ \\ Tania Regina Martins Machado ${ }^{2}$
}

Resumo: Este artigo parte de uma visão de política linguística para refletir sobre a implantação da língua espanhola no Brasil, de acordo com a lei 11.161/2005, e sua obrigatoriedade no Ensino Médio de escolas públicas e particulares. Além da observação dessa lei nacional, faz-se necessário discutir os pontos da LDB e dos PCN a respeito do estabelecimento dessa língua estrangeira como segunda língua. Para tanto, buscamos verificar como isso ocorre ao longo de sua história e, ainda, os fatores que contribuíram para a implantação dessa língua no país. Nesse sentido, trazemos a indagação: Por que a língua espanhola não foi implantada nas escolas da cidade de Araguatins? Destaca-se o fato de que o prazo estipulado pela lei já está deveras esgotado. Dessa forma, este artigo se dedica a discutir a implantação da língua espanhola no Ensino Médio das escolas públicas de Araguatins, buscando, então, saber os motivos do seu não cumprimento e chegar a uma reflexão sobre a revogação da "Lei do Espanhol", em 2017.

Palavras-chave: política linguística; lei 11.161/2005; língua espanhola; ensino médio.

Resumen: Este artículo parte de una visión de política lingüística para reflexionar sobre la implantación de la lengua española en Brasil, de acuerdo con la ley 11.161/2005, y su obligatoriedad en la Secundaria de escuelas públicas y particulares. Además de la observación de esa ley nacional, se hace necesario discutir los puntos de la LDB y de los PCNs sobre el establecimiento de esa lengua extranjera como segunda lengua. Para ello, buscamos verificar cómo esto ocurre a lo largo de su historia y, aún, los factores que contribuyeron para la implantación de esa lengua en el país. En ese sentido, traemos la indagación: ¿Por qué la lengua española no fue implantada en las escuelas de la ciudad de Araguatins? Se destaca el hecho de que el plazo estipulado por la ley ya está realmente agotado. De esta forma, este artículo se dedica a discutir la implantación de la lengua española en la Secundaria de las escuelas públicas de Araguatins, buscando, entonces, saber los motivos de su no cumplimiento y llegar a una reflexión sobre la revocación de la "Ley del Español", en 2017.

Palabras clave: política lingüística; ley 11.161/2005; lengua española; secundaria.

\footnotetext{
${ }^{1}$ E-mail: niveabersch@hotmail.com

2 Doutora em Linguística pela Universidade Federal de Santa Catarina e com pós-doutorado em Letras pela Universidade Federal do Tocantins. Docente da Universidade Estadual do Tocantins. Desenvolve pesquisas em Análise Crítica do Discurso. E-mail: tania-mm@ @otmail.com
} 


\section{Introdução}

O presente artigo visa realizar uma discussão sobre a proposta de ensino de espanhol língua estrangeira como disciplina curricular obrigatória no Ensino Médio (EM) de escolas públicas e particulares, recorrente ao cumprimento da Lei 11.161/2005, decretada em 05 de Agosto de 2005. Como referência para tanto, levamos em consideração uma perspectiva de política linguística para análise das orientações de documentos oficiais da educação, sobretudo, as Leis de Diretrizes e Bases (LDB), assim como os Parâmetros Curriculares Nacionais (PCNs). Por fim, trazemos também uma reflexão sobre a revogação da "Lei do Espanhol" em 2017.

A importância desse olhar a partir da política linguística para o ensino dessa língua se dá pela valorização socioeconômica do saber produzido na escola, haja vista que, nos últimos anos, a sociedade tem buscado melhorias e oportunidades no setor educacional. A abordagem desse tema se justifica, também, pela oportunidade de discutir a importância do ensino da língua espanhola na cidade de Araguatins, que ainda não está em cumprimento com a Lei $11.161 / 2005$.

Em busca de um cidadão cada vez mais preparado para a realidade mundial, hoje globalizada, é que essa lei propõe a implantação da língua espanhola nas escolas, oferecendo ao Ensino Fundamental II (EF-II) como facultativo e ao Ensino Médio (EM) como obrigatório o acesso a uma segunda língua estrangeira (LE), além do inglês.

Seguindo assim tais pressupostos, surge as indagações: O que os documentos oficiais trazem sobre o ensino de espanhol no Brasil? Por que na cidade de Araguatins ainda não se fez cumprir a Lei 11.161/2015? O que falta para sua implantação? Que discussão traz a revogação da Lei do Espanhol, em 2017?

Todas essas questões serão abordadas neste artigo. De modo que, para que se possa compreendê-las, será necessário descrever como surgiu o ensino da língua espanhola no Brasil, discutir os fatores que contribuíram para a implantação do Espanhol no país, entre outras temáticas relacionadas. Por fim, propomos o cumprimento dessa Lei para as escolas da cidade de Araguatins.

De acordo com a pesquisa bibliográfica levantada, faz-se, neste artigo, um procedimento metodológico qualitativo, descritivo e interpretativo, alicerçado em documentos oficiais da educação direcionados ao ensino de LEs, em especial a espanhola. Associado a 
isso, é realizada uma pesquisa de campo através de questionários e entrevistas a entidades representantes do ensino da cidade de Araguatins.

Para tanto, tomaremos como base o estudo de alguns autores especialistas em políticas linguísticas para refletir sobre a importância da implantação do espanhol. Dessa forma, autores como Calvet (2007), Sedycias (2005) e Guimarães (2011) são trazidos para discutir a problemática levantada neste texto.

O decorrer deste se constitui das seguintes seções: A primeira delas é a Introdução, em que é apresentada a temática a ser abordada neste texto; já na segunda, fazem-se breves considerações sobre a história da língua espanhola no Brasil através de uma abordagem da política linguística; na terceira seção, discute-se sobre os fatores que contribuíram para implantação do espanhol no Brasil; na quarta, faz-se um levantamento dos documentos oficiais da educação bem como da proposta de implantação de espanhol nas escolas públicas de Araguatins; na sequência, são apresentados os procedimentos metodológicos para as entrevistas; $\mathrm{Na}$ análise, é abordado como se dá o ensino dessa língua em Araguatins e, por fim, são traçadas algumas Considerações finais deste texto.

\section{A língua espanhola e sua história política no Brasil}

Nesta seção será abordada a história da língua espanhola no Brasil desde uma perspectiva política. Assim, faz-se relevante destacar que seu estudo em território brasileiro tem sido considerado uma necessidade no campo educacional. Nesse contexto, vem-se propondo uma reflexão sobre o aprendizado do idioma atualmente no país, já que, política e economicamente, têm-se estreitado os laços com os países hispano-americanos.

Partindo do estudo da história sobre a presença dos espanhóis em terras brasileiras, vemos que desde muitos anos o ensino desse idioma estabelece vínculos com os brasileiros. Entre 1888 e 1930, foi intensificado esse fenômeno com a colonização do Brasil. Em busca de riquezas, os imigrantes espanhóis migraram para terras americanas. Eles passavam por diversos problemas socioeconômicos na Espanha e se estabeleceram em colônias por toda a América. Segundo Francisco Moreno Fernández,

mais de quatro milhões de imigrantes, dos quais $12 \%$ eram espanhóis (...) ocuparam as terras das regiões Sul e Sudeste em consequência das graves crises econômicas que acometiam a Espanha desde meados do século XIX (FERNÁNDEZ, 2005, p. $18)$. 
As informações apresentadas por esse autor contribuem para esta abordagem de forma linear e de maneira sintetizada do período histórico de um sistema educativo brasileiro que inclui a língua espanhola para ser estudada nas escolas. Da mesma forma, temos o artigo $A$ obrigatoriedade do ensino de espanhol no Brasil, de Fernanda Maria Grosso Lisboa (2009), que discorre sobre os principais pontos da história dessa língua no país. Segundo a autora, o ensino dessa língua tem início em 1919 com a institucionalização da disciplina no Colégio Pedro II, no Rio de Janeiro. Na instituição, assumida pelo professor Antenor Nascentes, seu ensino era de livre escolha do aluno, ou seja, a disciplina era optativa e concorria com o inglês.

Nesse mesmo período, surge nesse contexto a primeira Gramática da Língua Espanhola para o ensino de espanhol entre os brasileiros. Ela trouxe uma nova visão ao ensino de espanhol no país, como relata A. Guimarães:

\begin{abstract}
A inclusão do ensino de espanhol no sistema educativo brasileiro tem início em 1919, com a abertura de concurso para a cadeira de espanhol no Colégio de Pedro II, em decorrência do aumento de subvenção para a criação da cadeira, aprovado pela Lei 3.674, de 7 de janeiro de 1919. A cadeira de espanhol foi criada em reciprocidade ao ato do governo do Uruguai que criou uma cadeira de português [4]. Em março do mesmo ano, o Colégio Pedro II abriu concurso para uma cadeira de espanhol, e em 5 abril aprovou o programa de ensino. O primeiro professor a assumir foi Antenor Nascentes (1886-1972). Em 1920, Nascentes publicou o livro Gramática da Língua Espanhola, pela Companhia Editora Nacional, primeira gramática de espanhol publicada no Brasil (GUIMARÃES, 2011, p. 2).
\end{abstract}

Contemporaneamente a essa publicação, a década de 1920 foi marcante para o Brasil, com grandes mudanças políticas e educacionais, como por exemplo, o crescimento industrial e populacional que consequentemente desenvolveu muitas cidades. Assim como também foi importante o abalo político ocasionado pela reivindicação feita na Semana da Arte Moderna em busca da valorização da cultura do país. Segundo Oliveira,

\footnotetext{
Além do crescimento industrial, do desenvolvimento das cidades e do aumento da população, as sucessivas tentativas de levantes que marcaram a década de 20 , assim como a Semana de Arte Moderna de 22, abalaram sensivelmente as estruturas políticas e culturais da chamada República Velha (OLIVEIRA, 2010, p. 189).
}

Outro momento marcante de nossa história ocorre em 1942. O então presidente Getúlio Vargas determina em seu governo a proibição do uso de LEs, como a língua alemã e italiana, por exemplo. Tal medida significou a tentativa de sufocar as colônias existentes no 
sul do país. Segundo Orlandi (2009, p. 113), seu objetivo era a nacionalização do ensino que “exerceu estreita censura no âmbito linguístico e cultural assim como no controle do crescimento e da convivência social". Falar LEs em terras brasileiras, nessa época, era considerado "crime idiomático". O Estado determinava, assim, qual a língua que se devia falar.

Essa especificação de se falar, em território brasileiro, apenas a língua portuguesa (LP) visava a manutenção do poder centralizado no Estado. Essa proibição não foi destinada a uma só LE, mas acaba sendo abrangente à língua espanhola, visto que os estados sulistas fazem fronteiras com países hispano-falantes.

Nos decretos então emitidos, Vargas reage contra o estrangeirismo descrito no Decreto Lei n.1545, de agosto de 1939, nos Artigos 85, 86 e 87. Trata-se, nesse sentido, de um período autoritário de nacionalismo exacerbado que exercia forte influência sobre a cultura e o conhecimento. Tais restrições linguísticas podem ser observadas na redação desse Decreto Lei:

Em todas as escolas rurais do país, o ensino de qualquer matéria será ministrado em português, sem prejuízo do eventual emprego do método direto no ensino de línguas vivas. 1. As escolas a que se refere este artigo serão sempre regidas por brasileiros natos. 2. Nelas não se ensinará idioma estrangeiro a menores de 14 anos (BRASIL, 1939, p. 10).

Observa-se, com isso que a direção em que seguia seu governo atingia fortemente aos imigrantes, pois tinha o objetivo de nacionalização do ensino em torno da LP. Graças a isso, Vargas era comumente atrelado ao julgamento de uma ideologia nazista, pois o estrangeirismo era totalmente monitorado pelo Estado, o que levou a proibição do ensino das LEs e sua dispersão cultual.

Por conseguinte, com a Reforma Capanema, através das medidas afim de reestruturação da educação nacional, torna-se obrigatório o ensino do espanhol no Colegial, juntamente com o francês e o inglês. É interessante observar que todas essas línguas constituíam a Educação Básica (EB) da época. Isso porque o Ginásio ${ }^{3}$ teria a obrigatoriedade de ensinar o Latim, o Francês e o Inglês. Com a criação da Lei Orgânica do Ensino Secundário, o ministro Gustavo Capanema destaca no Decreto Lei $n^{\circ}$ 4.244, de 09/04/42, as

\footnotetext{
3 Até 1971, no Brasil, o Ginásio constituía o estágio educacional que se seguia ao ensino Primário e que antecedia o ensino Colegial. Correspondia os quarto anos finais do atual ensino fundamental.
} 
finalidades do Curso Secundário, com atenção especial ao prosseguimento nos estudos superiores, conforme pode ser observado no trecho dessa lei a seguir:

1. Formar, em prosseguimento da obra educativa do ensino primário, a personalidade integral dos adolescentes. 2. Acentuar e elevar, na formação espiritual dos adolescentes, a consciência patriótica e a consciência humanística. 3. Dar preparação intelectual geral que possa servir de base a estudos mais elevados de formação especial (art. 1º) (BRASIL, 1942, p. 5798).

Portanto, essa foi a primeira vez que o espanhol foi inserido no Ensino Médio como disciplina obrigatória no intuito de reorganização da educação nacional.

\subsection{Lei de Diretrizes e Bases e Mercosul como aliados do ensino do espanhol}

Nesta seção nos dedicamos a tratar da consolidação e do processo de integração educacional, bem como do estreitamente de laços entre os países da América do sul e o Brasil. Assim, em 1961, surgiu a primeira Lei de Diretrizes e Bases (LDB) aprovada pela Lei $n^{\circ}$ 4.024 durante o governo de João Goulart. Lamentavelmente, ela não reconhece as LEs e retira a obrigatoriedade do ensino de espanhol em meio a importante movimento de educação popular em todo Brasil. Das línguas ensinadas no período desde a reforma Capanema até a LDB, para Rodrigues,

O espanhol foi, entre as três línguas modernas obrigatórias - ao lado do francês e do inglês -, aquela que desfrutou do menor poder de adesão na estrutura curricular desse período, devido a sua presença praticamente simbólica nos cursos Clássico e Científico $^{4}$ (contando com apenas um ano de estudo) e ao pouco tempo de que dispôs para poder se consolidar nesse nível de ensino (RODRIGUES, 2012, p. 17).

Portanto, percebe-se que até então o ensino de espanhol não era valorizado pelos governos e nos projetos por eles implantados. É do Estado o poder de escolha da língua a ser ensinada. Assim mesmo, quando foi obrigatório, o ensino dessa língua teve sua carga minimizada. Essa restrição de carga horária acaba comprovando o total descaso quanto ao ensino dessa língua nas escolas.

\footnotetext{
${ }^{4}$ Até 1967, o Ensino Médio era dividido em três cursos e compreendia o curso Científico, curso Normal e o curso Clássico que na sequência passou a ser chamado de Colegial.
} 
Já em 1971, há uma reforma na educação, com a Lei de Diretrizes e Bases da Educação Nacional promulgada com a Lei 5.692, mudando a terminologia de Ensino Primário e Secundário para Ensino de $1^{\circ}$ e $2^{\circ}$ graus. No entanto, o que não houve foram mudanças quanto ao ensino de LEs. Porém, em 1976, há um resgate do ensino de LE decretando obrigatória no ensino de $2^{\circ}$ grau. Logo em seguida surgiram as associações de professores, as quais contribuíram para o processo de ensino-aprendizagem de LEs apoiado por programas que se desenvolveram nessas associações. No artigo $O$ Ensino de Espanhol no Brasil: História de um processo em Construção, de Catya M. A. de Araujo, fazem-se alguns apontamentos acerca desse movimento. Dessa forma, o

\begin{abstract}
surgimento de associações de professores como a TESOL (Professores de inglês e Falantes de outras línguas), a APEERJ (Associação de professores de espanhol do Estado do Rio de Janeiro), APEESP (Associação de professores de Espanhol do Estado de São Paulo) assim como a criação de fundações (APLIESP, FENEIS, ALAB, SIPLE 5 ) (ARAUJO, 2010, p. 243).
\end{abstract}

Esse movimento dá mostras de que, nas últimas décadas do século $\mathrm{XX}$, o Brasil recebe influência dos países hispano-falantes, devido, em grande medida, às empresas espanholas que se instalaram no país. Com isso, passam a estreitar o relacionamento e fazer tratados com países vizinhos como a Argentina, Paraguai e o Uruguai, firmando assim o Tratado do Mercado Comum do Sul (MERCOSUL). Assim,

Em 1991, foi promulgado o Tratado para a Constituição de um Mercado Comum entre a República Argentina, a República Federativa do Brasil, a República do Paraguai e a República Oriental do Uruguai (Tratado MERCOSUL), através do Decreto $\mathrm{n}^{\circ} 350$ de 21 de novembro (BRASIL, 1991, p. 26443).

Com esse tratado, novas oportunidades foram geradas dentro do Brasil. Nesse momento, o Instituto Cervantes chega a São Paulo e, em 2000, ao Rio de Janeiro. Esse instituto foi criado para promover cursos de formação para professores de espanhol, assim como ensinar a própria língua materna aos brasileiros.

Com a promulgação da nova LDB, em 1996, no governo de Fernando Henrique Cardoso, passa a ser obrigatória uma língua estrangeira moderna (LEM) no âmbito do EM, de acordo com a escolha da comunidade. Além disso, deve haver um segundo idioma como

\footnotetext{
${ }^{5}$ TESOL - Theachers of English to Speakers of Other Languages (Professores de inglês e falantes de outras línguas).
} 
disciplina optativa, ofertada de acordo as possibilidades existentes da instituição, conforme artigo $36^{\circ}$, inciso III, da LDB/96:

Será incluída uma língua estrangeira moderna, como disciplina obrigatória, escolhida pela comunidade escolar, e uma segunda, em caráter optativo, dentro das possibilidades da instituição (BRASIL, 1996, s/p).

Nota-se que nesse artigo da LDB, quando voltada a uma LEM, cria-se uma expectativa de ser essa a língua inglesa seja pelo seu status e por sua valorização comercial. Porém, em nenhum momento está explícita a escolha de tal idioma. Tanto na resolução de 1976 quanto na LDB de 1996 há referência à inclusão de uma LE e não há uma especificação da mesma.

A valorização dos mercados consumidores de tecnologia e produtos importados de países asiáticos e investimentos realizados na Espanha foram fatores que fortaleceram o país para a ascensão de suas relações econômicas com o Brasil, na década de 90. A língua espanhola passa, então, a quebrar barreiras e a assumir status de segunda língua mundial, tornando-se reconhecida, também, devido à expansão do espanhol com a redemocratização da América Latina.

\title{
1.2 A Lei $n^{\circ} 11.161$ de 05 de Agosto de 2005
}

Nesta subseção é apresentada a Lei no 11.161/2005. A respeito disso, Chaguri destaca que

\begin{abstract}
Para que o espanhol fosse solidificado como componente curricular no país, para atender a nova configuração político-econômica do país, o presidente da República, Luiz Inácio Lula da Silva, sancionou no dia 5 de agosto de 2005 no Palácio do Planalto, a Lei $\mathrm{n}^{\mathrm{o}} 11.161$ que torna obrigatória a oferta da língua espanhola nas escolas públicas e privadas de ensino médio. Diante disso, a Lei n ${ }^{\circ} 9.394$ de 20 de Dezembro de 1996 especifica o artigo 36, inciso $3^{\circ}$, da Lei de Diretrizes e Bases da Educação Nacional - LDB, tornando obrigatório o ensino do espanhol na educação média (CHAGURI, 2012, p. 69).
\end{abstract}

Com a sanção da nova Lei de $n^{\circ} 11.161 / 2005$, a educação no Brasil toma um novo passo para com o ensino do espanhol no EM das escolas públicas e privadas. Ela vem em complemento à LDB que expedia apenas como obrigatória nesse nível de ensino uma LEM.

De acordo a LDB (BRASIL, 1996, p. 27 - Seção IV, Art. 35, Inciso III), “será incluída uma LEM, como disciplina obrigatória, escolhida pela comunidade escolar, e uma segunda língua, em caráter optativo, dentro das prioridades da instituição". A língua espanhola se 
constitui como uma segunda opção, ou melhor, é facultativa e deixada para ser ofertada no Ensino Fundamental, perante a Lei em questão.

Conforme a Lei sancionada, pode-se observar que o governo brasileiro estipulou um prazo determinado de cinco anos para se adequar e realizar o cumprimento dos autos com a implantação do ensino obrigatório de espanhol nas escolas. Foram, portanto, traçados objetivos para o ensino da disciplina, assim como para o desenvolvimento das metodologias de ensino, a fim de auxiliar os professores e as escolas no desempenho de seu trabalho. Araújo destaca que

Para tanto, o passo seguinte sobre o panorama histórico do ensino de línguas no Brasil a ser tratado, seguirá em relação aos objetivos da disciplina e metodologias da língua espanhola. Então, para complementar as LDBs que define e regulariza o sistema de educação brasileiro, foram publicados os PCNs (Parâmetros Curriculares Nacionais) com objetivo de auxiliar o professor e as escolas no desempenho de seu trabalho apresentando propostas de reorientação curricular feitas pela Secretária e Ministério de Educação. Servirão de estímulo e apoio à reflexão sobre a prática diária, ao programa de aulas e, ademais, ao desenvolvimento do currículo da escola, contribuindo ainda para a atualização profissional (ARAÚJO, 2010, p. 247).

Percebe-se, então, que no governo Lula o ensino da língua espanhola ganhou status de obrigatoriedade. Observa-se, porém, na subseção seguinte, outra mudança nesse cenário.

\subsection{Revogação da Lei 11.161/2005 em 2017}

Nesta seção apresentamos como se deu o passo seguinte à obrigatoriedade do ensino do espanhol no EM, decretada em 2005. Em 16 de fevereiro de 2017, no governo do presidente Michel Temer que tem como Ministro da Educação Mendonça Filho, é proposta a nova reforma do EM. Essa reforma revoga a Lei $n^{\circ} 11.161 / 2005$, que até então tinha como obrigatória do seu ensino nas escolas públicas e particulares. Nesse sentido, a reforma

\footnotetext{
Altera as Leis nos 9.394, de 20 de dezembro de 1996, que estabelece as diretrizes e bases da educação nacional, e 11.494, de 20 de junho 2007, que regulamenta o Fundo de Manutenção e Desenvolvimento da Educação Básica e de Valorização dos Profissionais da Educação, a Consolidação das Leis do Trabalho - CLT, aprovada pelo Decreto-Lei no 5.452, de 1o de maio de 1943, e o Decreto-Lei no 236, de 28 de fevereiro de 1967; revoga a Lei no11.161, de 5 de agosto de 2005; e institui a Política de Fomento à Implementação de Escolas de Ensino Médio em Tempo Integral (BRASIL, 2017, s/p).
} 
Com a nova proposta, a língua inglesa volta a ter obrigatoriedade exclusiva na EB, dando apenas a oportunidade de oferta de outra LE como optativa, sendo assim sugerida a língua espanhola. Por conseguinte, é comprometido todo o processo de construção da inserção do ensino de espanhol na educação brasileira. Nesse sentido, o texto da reforma estabelece no Art. $3^{\circ}$, Parágrafo $4^{\circ}$,

$\S 4^{\circ}$ Os currículos do ensino médio incluirão, obrigatoriamente, o estudo da língua inglesa e poderão ofertar outras línguas estrangeiras, em caráter optativo, preferencialmente o espanhol, de acordo com a disponibilidade de oferta, locais e horários definidos pelos sistemas de ensino (BRASIL, 2017, s/p).

Diante do fato existente sobre a implantação da língua espanhola no currículo educacional do Brasil, levantam-se vários questionamentos, argumentos e interpretações a respeito das intensões e interesses políticos, sociais e econômicos do poder sobre a educação.

\section{Fatores contribuintes para a implantação da língua espanhola no Brasil}

Depois de se traçar uma linha do tempo sobre a evolução do ensino da língua espanhola no Brasil e elencar as diferentes formas com que integrou nosso sistema de ensino, passamos a tratar dos possíveis fatores que contribuíram para essa disseminação na educação. Para tanto, recorre-se à perspectiva de política linguística. Em seus estudos sobre esse campo, Calvet (2007, p. 11) afirma que a "política linguística" está associada ao plurilinguismo e sua gestão, assim como, a mudanças políticas que levam as alterações das línguas a comunidades para integração da cidadania.

Nesta seção, apontam-se, então, alguns fatores que se destacam na historicidade da língua espanhola no Brasil. De acordo com as reivindicações de movimentos sociais e as ações do Estado nesse campo, torna-se necessário, neste artigo, assumir a perspectiva da política linguística com o objetivo de refletir sobre o lugar que essa língua pode ou deve ocupar no processo educativo brasileiro, como enfocam as Orientações Curriculares para o Ensino Médio (OCEM). Assim, essas orientações contribuem ao trazerem, no trecho a seguir, uma

reflexão sobre a maneira possível de trabalhá-la com o máximo de qualidade e o menor índice de reducionismo, um reducionismo a que, ao longo da história, se viu 
afetada a nossa relação com a Língua Espanhola e com os povos que a falam (BRASIL, 2006, s/p).

Assim, como se pôde observar na seção que trata das imposições à língua espanhola no Brasil e quanto ao ensino desse idioma em nossa educação é que o planejamento se faz importante. Dessa forma, é necessária uma análise de perspectiva a médio ou a longo prazo, passando por uma fase de avaliação até sua execução. De modo que política linguística surge como contribuição valorosa para os questionamentos de caráter social e político que envolvem a implantação do ensino de espanhol no país.

Portanto, a política linguística traz a reflexão de ação, do poder do Estado, sobre a inclusão da língua espanhola na educação brasileira. A respeito disso, de acordo com o que Calvet (2007) destaca, somente o Estado possui e perpassa o estágio de planejamento, sendo o único detentor do poder para pôr em prática suas escolhas políticas.

Em tempos globalizados, de desenvolvimento tecnológico, com contrastes econômicos e culturais na sociedade, o processo de ensino-aprendizagem deve ser valorizado, aproximando a população cada vez mais de um mundo promissor. E muitas são as necessidades e os critérios apontados para implantação do estudo de um novo idioma, como: o comércio, a indústria, a política, a cultura, a arte e a literatura.

\subsection{Língua, sociedade e cultura}

Estudiosos como Robinson (1985), Tomalin e Sternpleski (1996) e Bennett (1997 apud MEYER, 2008) se referem à língua e à cultura como intrinsecamente ligadas. Segundo esse pensamento, o sujeito é constituído por linguagem, por isso o estudo da LE não se restringe apenas a traduções de vocabulários ou à aplicação de regras de uma língua para outra, mas em unir saberes culturais de uma determinada língua. Neste caso, nos referimos especialmente à língua espanhola, um instrumento de comunicação que ensina a realidade vivenciada em conjunto com a língua materna.

Com a globalização as pessoas têm ido cada vez mais em busca de novas informações e a cultura hispânica tem sido de grande valor para esse processo social e cultural. Ao contribuir para a superação de tais anseios, o espanhol tem ganhado cada vez mais espaço entre os brasileiros.

Nesse cenário, as relações comerciais do MERCOSUL têm sido um vínculo de comunicação internacional que perpassam os grandes investimentos, valorizando a língua 
espanhola no Brasil. Fato que torna o idioma cada vez mais presente entre nós através da música, literatura, esporte, culinária e manifestações artísticas. Assim, esses países entrelaçam suas culturas através das fronteiras. Nesse sentido, Sedycias destaca que

\footnotetext{
o sucesso adquirido nos últimos anos pela música e literatura hispânica, a nível internacional é uma realidade, como é a simpatia que a Espanha causa em seus eventos artísticos e culturais, assim como, no esporte (SEDYCIAS, 2005, p. 21).
}

Está explícito, nas palavras desse autor, que, devido a essa proximidade dos países, criam-se afinidades culturais entre os hispano-falantes e os brasileiros. A partir de elementos como esses e nesse contexto, observamos que a língua espanhola passa a ser valorizada e nos parece coerente que ela volte a ser incluída na grade curricular da EB.

\subsection{Língua espanhola e educação}

Conforme vimos, cabe às autoridades públicas o planejamento linguístico de modo a promover uma inter-relação entre o aprendizado pessoal, cultural e linguístico. A inclusão de mais uma LE na grade curricular do EM, o espanhol, oportunizará aos alunos, além do conhecimento de mais um idioma, seu desenvolvimento cultural, político e econômico.

Uma medida como essa poderá fazer com que os mesmos percebam as diferenças linguísticas e sociais, desenvolvendo uma percepção crítica do mundo que os cerca. Relativamente a isso, Garcia Canclini (1995) discorre sobre o avanço tecnológico dentro do meio de comunicação em exercício da cidadania, pois tal avanço impacta a convivência social e a reorganização do trabalho. Mais adiante dispomos dessa ideia do autor, de que

\footnotetext{
a escola que se delineia como ideal é aquela voltada para a construção de uma cidadania consciente e ativa, que ofereça aos alunos bases culturais que lhes permitam identificar e posicionar-se frente as transformações em curso e incorporarse na vida produtiva (CANCLINI, 1995, p. 10).
}

Contudo, a partir da Lei 11.161/2005, que propõe a língua espanhola como obrigatória nas escolas públicas e privadas de EM e facultativo nos currículos plenos de $6^{\circ}$ ao $9^{\circ}$ ano do $\mathrm{EF}$, considera-se que é imprescindível a presença do ensino do espanhol no Brasil. Ao pensar em seu processo de aprendizado, é preponderante o fato de que ele guarda semelhanças com a língua nacional, aparentemente de fácil compreensão para os lusófonos brasileiros. No 
entanto, há relevantes diferenças linguísticas, o que faz necessário um estudo mais cuidadoso do espanhol, desmistificando a ideia de aprendizagem fácil.

De acordo com os PCNs, “as Línguas Estrangeiras assumem a condição de ser parte indissolúvel do conjunto de conhecimentos essenciais que permitem ao estudante aproximarse de várias culturas e, consequentemente, propiciar sua interação num mundo globalizado" (BRASIL, 1999, s/p). Assim, espera-se que alunos e professores se envolvam no processo de feedback, desenvolvendo no ensino de língua espanhola, portanto, um aprendizado cada vez mais inserido nesse contexto, para que se sintam identificados com a cultura latino-americana.

Consideramos, no presente artigo, a importância da implantação de espanhol nas escolas públicas brasileiras. Dessa forma, os alunos podem adquirir um conhecimento significativo a respeito da cultura dos países que utilizam a língua espanhola como língua materna. Haja vista que muitos desses países fazem fronteira e integram o mesmo grupo econômico que o Brasil, além de partilhar com este questões históricas, econômicas e sociais análogas.

Além disso, a cultura hispânica de destaca por suas influências na globalização de informações, facilitada pelas diversas fronteiras do Brasil com países cuja língua oficial é o espanhol. Esse contato é geograficamente favorecido e os brasileiros acabam adquirindo afinidade com suas músicas, manifestações artísticas, literatura, etc., através de viagens, vínculos de sangue e empregatícios, entro outros.

A isso, relacionamos a elaboração de trabalhos sociais, projetos inclusivos e dinâmicas que favorecem a comunidade, os quais fazem parte da proposta dos PCNs desde a EB, para se desenvolver um cidadão atuante na sociedade. O professor, no entanto, tem mais possibilidades de praticar esse tipo trabalho quando existe um retorno satisfatório movido pela afinidade e curiosidade do aluno. Assim como relata o PCN:

\footnotetext{
A escola não muda a sociedade, mas pode, partilhando esse projeto com segmentos sociais que assumem os princípios democráticos, articulando-se a eles, constituir-se não apenas como espaço de reprodução mas também como espaço de transformação (...). A concretização desse projeto passa pela compreensão de que as práticas pedagógicas são sociais e políticas e de que não se trata de educar para a democracia - para o futuro. Na ação mesma da educação, educadores e educandos estabelecem uma determinada relação com o trabalho que fazem (ensinar e aprender) e a natureza dessa relação pode conter (em maior e em menor medida) os princípios democráticos (BRASIL, 1999, p. 25-26).
} 
Relacionamos, portanto, a proposta dos PCN à temática discutida neste artigo. Em busca de um cidadão cada vez mais preparado para a realidade mundial, hoje globalizada, é que se propõe a continuidade da implantação do ensino da língua espanhola nas escolas brasileiras, ofertando-a ao Ensino Fundamental II como facultativa e ao EM como obrigatória, de modo que tenham o acesso ao espanhol, além do inglês.

\section{Procedimentos metodológicos}

Nesta pesquisa, integra-se o estudo documental, através da síntese de leis, diretrizes e parâmetros que regem o ensino de LE no país, com especial observação para o espanhol, ao estudo de campo, dado que são realizadas entrevistas e aplicados questionários a pessoas que ocupam cargo de chefia em órgãos voltados para a educação na cidade de Araguatins.

Com o objetivo de analisar o processo de implantação da língua espanhola na grade curricular no ensino médio das escolas públicas estaduais de Araguatins é que se fez necessário um levantamento junto à Diretoria Regional de Ensino de Araguatins (DREA) e às escolas públicas estaduais, para saber o motivo da demora no cumprimento da Lei 11.161/2005, que parte da obrigatoriedade do ensino de espanhol como LE.

Para levantamento de dados da pesquisa, conforme os Anexos, foram realizadas entrevistas com perguntas abertas e fechadas com a Assessoria de Línguas das escolas de EM da Delegacia Regional de Ensino de Araguatins (DREA) e com a atual direção do Centro de Ensino Médio, hoje Colégio da Polícia Militar (CPM). A aplicação desses instrumentos de pesquisa permitiu a realização de uma leitura mais ampla sobre a situação da implantação do Espanhol nos currículos plenos de ensino nas escolas públicas estaduais de EM, em Araguatins.

Além disso, com o objetivo de entender a importância da implantação da Língua Espanhola nas escolas e para a cidade de Araguatins, considerando a presença do curso de formação universitária de professores de português e espanhol, foi realizada também uma entrevista com a direção do campus da Universidade Estadual do Tocantins (UNITINS), em Araguatins. Por fim, tais dados foram contrastados com a revogação da Lei 11.161/2005, em 2017.

\section{0 ensino da língua espanhola em Araguatins}


Conforme exposto nas seções anteriores, o ensino da língua espanhola no Brasil tem passado por modificações em sua grade curricular do EM, ora se fazendo obrigatória ora facultativa, levantando questionamentos sobre os reais motivos de sua importância social e política para sua implantação.

Para a realização desta pesquisa, foi feita uma entrevista com perguntas abertas e fechadas à Assessoria de Línguas da DREA sobre o cumprimento da Lei 11.161/2005, sendo que seu cumprimento se deu apenas em 2017. De acordo com a Assessoria (ver Anexos), até 2016 havia apenas dois servidores em toda Regional, habilitados para ministrar aulas de espanhol, porém, ambos lotados para Augustinópolis. Portanto, devido a essa falta de profissionais habilitados na área de Letras/Espanhol é que ainda não havia sido implantado o ensino do idioma.

Sobre o último concurso público do Estado do Tocantins, em que foram ofertadas 11 vagas distribuídas em 11 regionais, sendo que uma vaga foi destinada a Araguatins, de acordo com as respostas dadas, essa vaga não foi preenchida, pois o candidato não possuía os requisitos de formação adequados para a ocupação do cargo.

E como meio de justificar essa deficiência, o Conselho Estadual de Educação (CEE) lançou, o parecer n³30/2011 sobre as normas de oferta da língua espanhola no Estado. Este não teria tão somente a finalidade de justificar, mas de dispor sobre as condições para que a Lei pudesse ser cumprida. Faz-se notável o tom pejorativo utilizado quando o conselho diz: "Mesmo por que não se pode dar aquilo que não se tem", deixando explícito que não havia condições para o cumprimento da Lei, cabendo a prorrogação do prazo para sua completa implementação no ano letivo de 2014, fato que não aconteceu.

Em uma conversa informal com Assessoria da Área de Linguagens, há referência sobre um projeto de formação de um Centro de Línguas em que seriam ofertadas aos alunos aulas de línguas, além de capacitações aos professores de Espanhol. Essa medida contribuiria com a ascensão da educação na cidade, o que infelizmente foi interrompido por motivos políticos e de poder, troca de governo, por aqueles que não têm o interesse para com a melhoria da sociedade. Essa compreensão é confirmado em Calvet quando diz que

De igual modo, o poder político sempre privilegiou essa ou aquela língua, escolhendo governar o Estado numa língua ou mesmo impor à maioria a língua de uma minoria. No entanto, a política linguística (determinação das grandes decisões referentes entre as línguas e a sociedade) (CALVET, 2007, p. 11). 
Em continuidade com o intuito de esclarecer o conhecimento da importância do espanhol no EM e a sua implantação em Araguatins, foi realizada uma entrevista com a atual direção do CPM (ver Anexos). Nessa oportunidade, afirmou-se que a escola promove o ensino do devido idioma desde o ano anterior, 2017, às primeiras séries do EM, embora tenha sido informado que há apenas uma professora de língua espanhola contratada pelo Estado.

Dando sequência à entrevista, a direção não soube dizer o porquê de a implantação ter ocorrido apenas nas primeiras séries, já que a escola recebeu livros didáticos também das demais séries, segunda e terceira. Parece que o fato de apenas algumas séries receberem o ensino de espanhol está relacionado à falta de contratação de profissionais da área. No entanto, ele justificou que faz parte da política da Secretaria Regional de Educação (SEDUC) tomar frente do processo de escolha da língua estrangeira a ser aplicada aos estudantes.

Conclui-se, portanto, que mesmo diante do referido em Lei acerca da obrigatoriedade do espanhol no EM, o Estado é quem tem o poder sobre as decisões de implantação e de pôr em prática aquilo que lhe convém. Isso está de acordo com o que Calvet (2007, p. 21) relata: “devemos admitir que, na maior parte dos casos, as políticas linguísticas são iniciativa do Estado ou de uma entidade que disponha no seio do Estado de certa autonomia política".

Ainda, segundo a direção da unidade, são feitos trabalhos voltados para o ensinoaprendizagem de espanhol, como aulas de reforço com as primeiras séries e minicursos com as outras, segundas e terceiras séries. Isso é possível através de parcerias com os estagiários e monitores do centro de Línguas da UNITINS. Quanto aos estudos da língua para o Exame Nacional do Ensino Médio (ENEM), ela afirma que haverá “aulões” incentivados pela própria Secretaria de Educação do Tocantins (SEDUC).

Isso se confirma na entrevista com a Assessoria de Línguas da DREA, que demostra com positividade os resultados da implantação do espanhol em 2017, quando aplicado o Simulado do ENEM. Segundo ela, muitos alunos optaram pela língua espanhola para realizar esse teste e apresentaram certa habilidade na resolução e interpretação dos textos, o que também comprovaria a eficiência na metodologia utilizada pelos formandos em Letras da UNITINS ao ministrarem os "aulões" e minicursos.

De acordo com o questionamento do cumprimento total da "Lei do espanhol", a direção do CPM fala sobre a importância do estudo da língua espanhola para seus alunos, quando reafirma sua perspectiva quanto à implantação do ensino do idioma nas demais turmas do EM para o próximo ano, período mais oportuno para levar o pedido à SEDUC. Portanto, 
percebe-se que a direção da escola concorda com o cumprimento total dessa Lei e que tem interesse em continuar com o ensino de espanhol nos próximos anos, a fim de melhorar o conhecimento cultural e linguístico de seus alunos.

No meio acadêmico, sobre o âmbito de formação de profissionais na área de língua espanhola, foi realizada uma entrevista com a direção do campus da UNITINS de Araguatins (ver Anexos). Ela forneceu as informações sobre a implantação do curso de graduação em Letras com habilitação em Português e Espanhol na cidade. O início do curso se deu na segunda metade do ano de 2014, com uma única turma com 51 alunos aprovados no vestibular, ao passo que hoje já são 5 turmas no total.

Surge, então, a pergunta do porquê da habilitação em Letras Português/Espanhol e não em Português/Inglês ou Português/Literatura, já que na cidade ainda não havia escolas com esse segundo idioma implantado. Surpreendentemente, a direção afirma que essa escolha não foi uma opção e sim uma predestinação. Isso já veio determinado pela sede da UNITINS, em Palmas - TO, não se sabendo ao certo os verdadeiros motivos da escolha dos cursos para este campus (Letras Português/Espanhol e Pedagogia).

Essa predestinação, segundo a direção do campus, foi uma assertiva, provando que o curso tem dado certo, pois o último vestibular teve o maior número de inscritos, além de alunos que passaram e se matricularam no curso de Letras Português/Espanhol, desde a sua implantação. De modo que, é possível relacionar à procura pelo curso ofertado pela unidade e a crescente demanda de profissionais habilitados na área.

A fim de se entender esse caso de política linguística e seus possíveis motivos para a implantação do curso de Letras com a habilitação também em espanhol em meio à sociedade araguatinense, faz-se importante destacar que a Universidade produziu bons resultados em seu processo de formação acadêmica, como confirma a direção desse campus.

Nesse sentido, a UNITINS alçou ao mercado de trabalho profissionais habilitados em língua espanhola para ocuparem os lugares de professores do devido idioma nas escolas estaduais de Araguatins.

Outro trabalho passível de ser realizado também por esses egressos é o de intérprete turístico. Em seu depoimento, a direção do campus da UNITINS de Araguatins julga a cidade um lugar sazonal com eventos de veraneio, os quais trazem turistas de diversos lugares do mundo, principalmente hispano-falantes, como os espanhóis, por exemplo. Da mesma forma como refere Sedycias (2005), são muitos os motivos que podem ser apontados como critérios 
de estudo de um determinado idioma como: o comércio, a indústria, a política, a cultura. Enfim, variadas são as demandas que remetem às línguas de grande circulação neste mundo globalizado.

A direção afirma que desde o início do curso, a UNITINS teve grande dificuldade na contratação de profissionais da área de espanhol capacitados para ministração das aulas de graduação, tendo que buscá-los em outras cidades, como: Marabá - PA, Araguaína - TO e Imperatriz - MA. Porém, hoje vê com olhar favorável esse curso, e considera, com a formação dos primeiros acadêmicos habilitados na área, a facilidade que os campus de Araguatins e de Augustinópolis terão para contratação desses profissionais de língua espanhola na própria região.

Diante do exposto, a pesquisa revela uma grande satisfação, por parte das direções do CPM e da UNITINS, quanto à implantação do idioma nas grades curriculares do EM das escolas públicas de Araguatins. Assim como, também, o interesse dos alunos em estudar e aprender mais uma LEM, porém cabe às competências maiores as devidas providências quanto à implantação total do idioma.

Em meio à revogação da Lei do Espanhol, em 2017, ação que anula a obrigatoriedade do ensino do idioma, observamos que não houve preocupações ou qualquer demonstração de repúdio, por parte das entidades entrevistadas, devido ao não cumprimento total da Lei até o instante. Uma possível interpretação para isso seria porque tal decisão já fazia parte de sua realidade, a implantação da língua espanhola no EM, em Araguatins, constituiria uma ação que mudaria tal perspectiva.

\section{Considerações finais}

Neste artigo nos dedicamos a refletir sobre a política linguística no ensino de espanhol no Brasil. Dessa forma, discorremos sobre um levantamento histórico linear da importância que esse idioma oferece como ensino de uma LEM. A partir de uma retomada histórica, verificamos que a língua espanhola passou por vários processos de aprovação e desaprovações ao longo da sua implantação no país, prestando-se a diferentes finalidades políticas, sociais e econômicas. Esse mapeamento foi relevante para compreendermos o discurso cultural da sociedade sobre ela em meio aos conceitos de política linguística, baseados em Calvet (2007). 
Esta pesquisa também visou buscar os fatores contribuintes para implantação do ensino de espanhol durante o seu processo de institucionalização no Brasil, com o autor Guimarães (2011). Assim como também tratou da importância desse idioma frente às configurações pedagógicas do ensino do espanhol dentro da nossa sociedade, com base em Sedycias (2005). Objetivou-se, sobretudo, com esta investigação, verificar quais os motivos que fizeram a demora do cumprimento da Lei 11.161/2005, da obrigatoriedade da oferta desse idioma, nas escolas públicas estaduais de Araguatins, bem como, refletir sobre sua revogação em 2017.

Através das entrevistas aplicadas às direções do CPM e da UNITINS, campus Araguatins e à Assessoria de Línguas da DREA, chegamos à conclusão de que uma das causas da demora pela oferta do ensino de espanhol nas escolas foi a falta de profissionais capacitados na área de Letras com habilitação em espanhol. Além disso, contribuiu para esse quadro, a falta de interesse do poder público em fornecer capacitações aos profissionais para que pudessem exercer a função de professor dessa LE.

Observa-se, no entanto, que em nenhum momento da pesquisa a revogação da Lei 11.161/2005, em 2017, foi tida como um problema para as instituições voltadas para a educação no município. Mas cabe aqui ressaltar o tempo de preparo de profissionais na área de Letras/Espanhol, assim como a adequação das escolas durante anos, para assumirem futuros concursos incertos. Portanto, consideramos que a importância da implantação da língua espanhola na cidade de Araguatins se dá pela determinação das grandes decisões referentes às relações entre as línguas, neste caso o espanhol, e nossa sociedade.

Por fim, esperamos que esta pesquisa tenha cumprido seu papel de contribuir para a criação de melhores perspectivas quanto à implantação total do idioma na grade curricular como disciplina, ocupando espaço de uma segunda LEM nas escolas estaduais de Araguatins. Destaca-se o fato de que existe uma aptidão natural dos alunos para com o estudo do idioma, tendo em vista a proximidade do espanhol com nossa língua materna.

\section{Referências}

BRASIL. Decreto Lei n.1545, de agosto de 1939. Disponível em:

$<$ https://www2.camara.leg.br/legin/fed/declei/1930-1939/decreto-lei-1545-25-agosto-1939411654-publicacaooriginal-1-pe.html>. Acesso em: 12 dez. 2013. 
BRASIL. Decreto Lei n. 4.244 de 9 de abril de 1942. Lei Orgânica do ensino secundário. Disponível em: <http://www2.camara.leg.br/legin/fed/declei/1940-1949/decreto-lei-4244-9abril-1942-414155-publicacaooriginal-1-pe.html>. Acesso em: 12 dez. 2013.

BRASIL. Decreto n. 38.643 de 27 de junho de 1961. Disponível em:

<https://www.al.sp.gov.br/repositorio/legislacao/decreto/1961/decreto-38643-

27.06.1961.html>. Acesso em: 12 dez. 2013.

BRASIL. Constituição (1988). Presidência da República. Decreto $N^{\circ} 350$, de 21 de novembro de 1991. Promulgação do Tratado para a Constituição de um Mercado Comum entre a República Argentina, a República Federativa do Brasil, a República do Paraguai e a República Oriental do Uruguai e dá outras providências. Brasília, DF, 1991. Disponível em: <http://www2.camara.leg.br/legin/fed/decret/1991/decreto-350-21-novembro-1991-449399norma-pe.html>. Acesso em: 21 de jun. 2012.

BRASIL. Lei 13.415 de 16 de fevereiro de 2017. Disponível em <http://www.normaslegais.com.br/legislacao/Lei-13415-2017.htm>. Acesso em: 18 de abr. 2017.

CALVET, Louis-Jean. As políticas linguísticas. Isabel de O. Duarte; Jonas Tenfen; Marcos Bagno (Trads.). São Paulo: Parábola Editorial, 2007.

CANCLINI, Nestor García. Consumidores e cidadãos: conflitos multiculturais da globalização. Rio de Janeiro: Editora da UFRJ, 1995.

CHAGURI, J. P. As Vozes de uma Política de Ensino de Língua Estrangeira Moderna na Educação Básica do Estado do Paraná. Revista Acta Scientiarum Education. Maringá, v. 32 , n. 2, 2010, p. 225-236.

FERNÁNDEZ, Francisco Moreno. El Español en Brasil. In: SEDYCIAS, João. (Org.). O Ensino do Espanhol no Brasil: passado, presente, futuro. São Paulo: Parábola Editorial, 2005. p. 18-24.

FREITAS, L. M. A.; BARRETO, T. A. Construindo uma história: a APEERJ e o ensino de espanhol no Brasil. In: Anuario brasileño de estudios hispânicos. 2007. p. 65-69. 
GUIMARÃES, A. História do ensino de espanhol no Brasil. Scientia Plena. São Cristóvão Se. Vol. 7, n 11, p. 5501. 13 de novembro de 2011.

LISBOA, Maria Fernanda Grosso. A obrigatoriedade do ensino do espanhol no Brasil: implicações e desdobramentos. Tese (Doutorado em Linguística Aplicada no IEL). São Paulo: UNICAMP, 2009. p. 200-217.

ORLANDI, Eni P. Língua Brasileira e Outras Histórias. Campinas-SP, Editora RG, 2009

OLIVEIRA, L. E. Gramatização e escolarização: contribuições para uma história do ensino das línguas vivas no Brasil (1757-1827). São Cristóvão: Editora UFS e Aracaju: Editora Oviedo Teixeira, 2010.

OLIVEIRA, L. E. A historiografia brasileira da literatura inglesa: uma história do ensino de inglês no Brasil (1809-1951). 1999. 189 f. Dissertação (Mestrado em Teoria Literária).

Instituto de Estudos da Linguagem. Universidade Estadual de Campinas, Campinas.

Disponível em: <http://www.unicamp.br/iel/memoria/projetos/teses/tese19.doc >. Acesso em: 20 mar. 2018

RODRIGUES, Fernanda dos Santos Castelano. Leis e línguas: o lugar do espanhol na escola brasileira. Espanhol. V.16. Disponível em:

<http://www.espanhol.seed.pr.gov.br/arquivos/File/mec_exp_ensino/cap_um.pdf $>$. Acesso em: 20 jan. 2018.

SEDYCIAS, João. O ensino do espanhol no Brasil: passado, presente, futuro. São Paulo: Parábola Editorial, 2005. 


\section{ANEXOS}

\section{QUESTIONÁRIO À DIREÇÃO DA ESCOLA ESTADUAL DE ENSINO MÉDIO EM ARAGUATINS}

Nome da Escola: Centro de Ensino professora Antonina Milhomem - CPM. Escola da Polícia Militar.

Quantos professores de Língua Espanhola possuem na escola?

Somente uma

Para quais turmas é ofertada a disciplina? 
A todas as turma de $1^{\circ}$ ano

Por que a escola ofertou a disciplina somente aos $1^{\circ}$ anos?

Na realidade essa escolha faz parte da política da SEDUC.

Existe algum trabalho feito com as outras turmas? E o $3^{\circ}$ ano, como estão se preparando para o vestibular? Todos escolhem o inglês?

Não, nem todos escolhem o inglês nos vestibulares mas a escola oferece reforço escolar e minicursos com estagiários do Centro de Línguas da UNITINS. E ainda vão ter os aulões para um melhor aproveitamento no ENEM.

Quais as perspectivas de oferta total da língua espanhola em 2019?

No momento em que eu tiver oportunidade pedirei sim a SEDUC a língua espanhola na grade curricular das demais séries do Ensino Médio.

\section{ENTREVISTA À DIREÇÃO DA UNIVERSIDADE ESTADUAL DO TOCANTINS (UNITINS) - CAMPUS ARAGUATINS}

1. A UNITINS - campus Araguatins oferece hoje o curso de graduação em Letras/Espanhol. Em que ano o curso foi implantado? Quantas turmas de Letras/Espanhol possuem hoje?

O curso foi implantado em 2014.2 e já possui cinco turmas de Letras/Espanhol.

2. Na época em que foi implantado o campus em Araguatins, quais foram os critérios ou motivos na escolha do curso de Letras/ Espanhol.

$\mathrm{Na}$ verdade é que quando foi implantado a UNITINS - campus Araguatins que veio de Palmas, já veio predestinado a ordem de abertura dos cursos porque direito e enfermagem já havia em Augustinópolis.

3. Quais foram os resultados que obtiveram durante esses anos de vestibulares? O curso tem dado certo? 
Sim, o curso tem dado certo, obtivemos bons resultados porque o último vestibular que nós fizemos foi o maior número de inscritos de alunos que passaram e se matricularam para estudar o curso de graduação em Letras/Espanhol, então isso prova que o curso tem dado certo.

4. O que o curso traz de benfeitorias à cidade? As turmas de Letras /Espanhol realizam trabalhos sociais e/ou interagem com as escolas?

$\mathrm{O}$ curso traz de benfeitoria a cidade principalmente que a nossa região necessita muito de pessoas em letras com habilitação em Espanhol, pois a prefeitura e as cidades vizinhas já estão contratando os nossos acadêmicos que vão sair agora em julho, formando duas turmas, portanto já temos acadêmicos trabalhando na cidade, o que significa que a implantação do curso foi muito boa.

5. Este ano a UNITINS - campus Araguatins formará a primeira turma letrada em língua espanhola na modalidade presencial. Quais foram os pontos positivos e negativos durante todo o curso na visão da direção do campus?

Os pontos negativos durante o nosso curso foi à busca de profissionais habilitados em espanhol, tivemos que ir atrás de profissionais em Araguaína, Imperatriz e Marabá e o ponto positivo é que com a turma que irá formar agora em julho teremos profissionais habilitados pois agora fica mais fácil para a UNITINS - campus Araguatins e Augustinópolis terem esses profissionais na região.

Outro ponto importante com o curso de Espanhol, a nossa cidade de Araguatins é uma cidade turística e sazonal, nos meses de julho e dezembro a cidade recebe muitos turistas e desses turistas tem muitos que falam outros idiomas inclusive o espanhol e com a formação desses acadêmicos de Letras/ Espanhol eles podem estar contribuindo para o desenvolvimento do turismo em nossa cidade.

6. Como você recebeu a Revogação da Lei 11.161/2005, em 2017?

Eu vejo com tranquilidade pois a Universidade percebe que a cidade tem a necessidade dessa formação que é Letras/Espanhol e isso não está relacionado somente com formação de professores mas na condição de prestação de serviço à sociedade com o forte turismo na região. 


\section{ENTREVISTA COM A ASSESSORIA DE LÍNGUAS DA DELEGACIA DE ENSINO DE ARAGUATINS - DREA}

1. A Lei 11.161/2005 conhecida como "Lei do Espanhol" deu um prazo de cinco anos para o seu cumprimento. Por que a única escola estadual de Ensino Médio que havia em Araguatins implantou a disciplina de Língua Espanhola somente em 2017?

Por falta de profissionais habilitados na área. Até 2016 apenas dois servidores em toda Regional tinham habilitação.

2. Por que a disciplina foi ofertada somente ao $1^{\circ}$ ano do Ensino Médio? E por que em 2018 não abriu para as outras séries?

Por falta de profissional formado na área. Em 2016 o município de Augustinópolis tinha dois profissionais ministrando o Espanhol.

3. No último concurso público do Estado do Tocantins foram ofertadas 11 vagas distribuídas entre 11 regiões, sendo que uma vaga era destinada a Araguatins. Essa vaga foi preenchida?

Por a vaga não ter sido preenchida é que demorou-se tanto na implementação da disciplina na escola.

4. Qual a perspectiva para total implantação da língua espanhola nas escolas de ensino médio de Araguatins?

A perspectiva é que haja concurso para que este profissional formado em Letras/Espanhol tenha oportunidade de assumir.

5. Quais foram os resultados obtidos com a implantação do espanhol em 2017?

O único resultado que podemos mensurar por enquanto sobre a implantação do Espanhol é que nos simulados do ENEM, muitos alunos têm optado pela língua espanhola e apresentado certa 
DIÁRIO OFICIAL DO TOCANTIS DE 13 DE OUTUBRO DE 2011

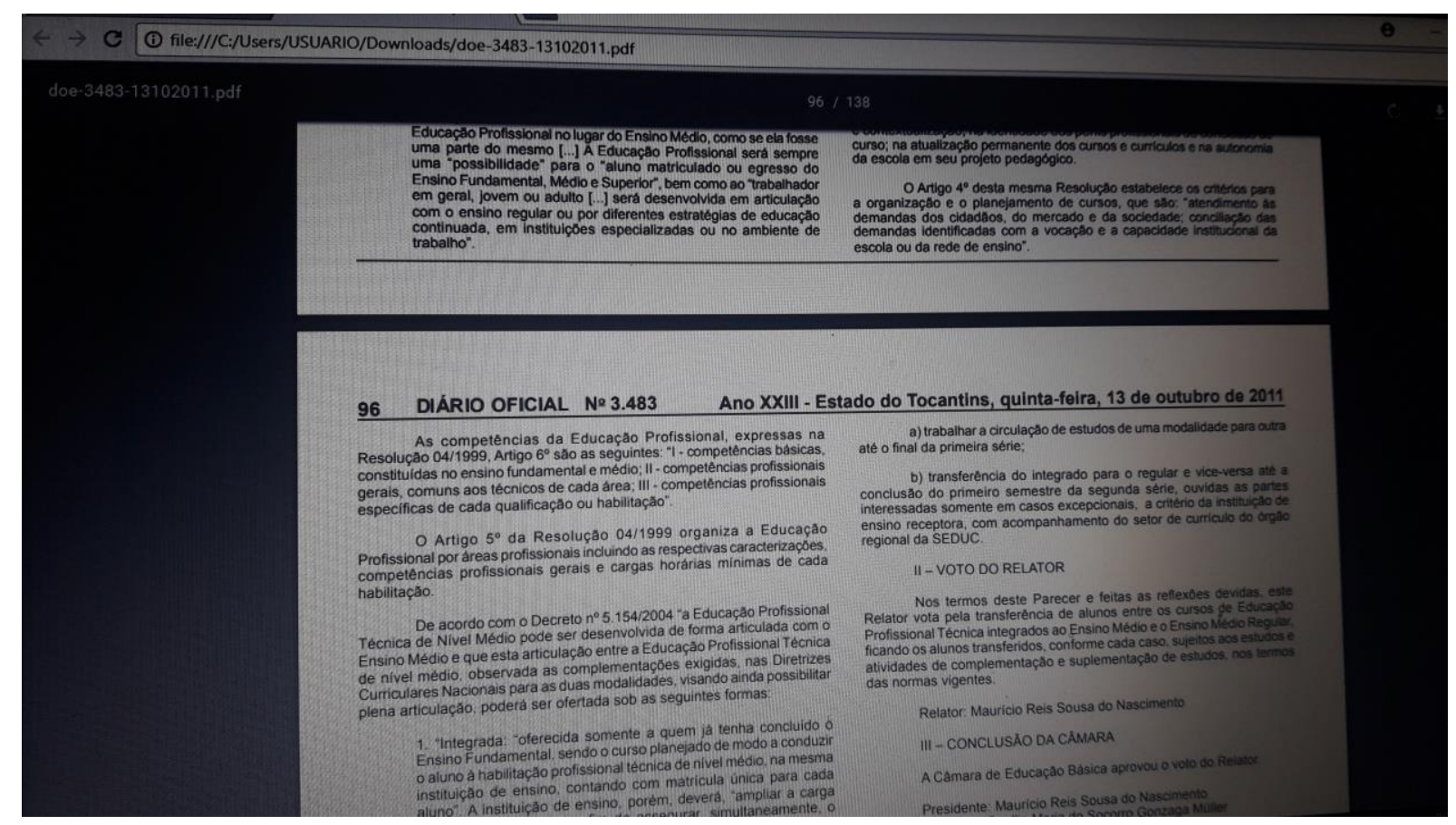

